\title{
Metastasis of Dermatofibrosarcoma from the Abdominal Wall to the Thyroid Gland: Case Report
}

\author{
Alexander Kreze Jr., ${ }^{1}$ Andrea Zápotocká, ${ }^{1}$ Tomáš Urbanec, ${ }^{1}$ Jiř́i Koskuba, ${ }^{1}$ Mikuláš Pura, ${ }^{2}$ \\ Pavel Vítek, ${ }^{3}$ Pavol Praženica, ${ }^{4}$ and Eva Traboulsi ${ }^{5}$
}

${ }^{1}$ 2nd Department of Internal Medicine, Faculty Hospital Bulovka, 18081 Prague, Czech Republic

${ }^{2}$ National Institute of Endocrinology and Diabetology, 03491 L'ubochňa, Slovakia

${ }^{3}$ Oncological Institute, 18081 Prague, Czech Republic

${ }^{4}$ Department of Otorhinolaryngology, Central Military Hospital, 16902 Prague, Czech Republic

${ }^{5}$ Department of Pathology, Central Military Hospital, 16902 Prague, Czech Republic

Correspondence should be addressed to Alexander Kreze Jr., krezejr@yahoo.com

Received 23 August 2012; Accepted 29 September 2012

Academic Editor: Jahn M. Nesland

Copyright (c) 2012 Alexander Kreze Jr. et al. This is an open access article distributed under the Creative Commons Attribution License, which permits unrestricted use, distribution, and reproduction in any medium, provided the original work is properly cited.

\begin{abstract}
Metastases in the thyroid gland are very rare. Even the rarer are sarcoma metastases. A 52-year-old woman was referred to our department for evaluation of a nodule in the right lobe of the thyroid gland. She had a history dermatosarcoma of the abdominal wall with known metastasis in the lung. Clinically she had neck pain and worsened swallowing. Objective assessment (ultrasound, computed tomography, and magnetic resonance) indicated a voluminous right lobe nodule with mechanical syndrome, and a fine-needle aspiration biopsy revealed a very suspicious malignant finding. After surgery, the diagnosis was metastasis of dermatofibrosarcoma protuberans. Subsequent treatment was radio- and chemotherapy.
\end{abstract}

\section{Introduction}

Thyroid gland tumors account for $0.5-1 \%$ of all malignancies [1]. According to the World Health Organisation (WHO) primary thyroid tumors are classified as epithelial and nonepithelial, benign or malignant, with a separate category for lymphomas and miscellaneous neoplasms [2]. Classification according to the Armed Forces Institute of Pathology (AFIP) gives priority to the cell of origin and incorporates, in each cell type, special tumor types and subtypes designated as "variants" [3]. Sarcomas according to WHO classification are class $\mathrm{V}$, while for AFIP classification they are A4.

Dermatofibrosarcoma protuberans (DFSP) is a rather uncommon soft tissue tumor of mesenchymal origin arising in the dermis. It is regarded as having intermediate malignant potential. DFSP accounts for less than $2 \%$ of all soft-tissue sarcomas (less than $0.1 \%$ of all cancers). The most common location is the trunk (50\%), proximal extremities (30\%), head and neck $(0 \%-15 \%)$, and rare cases involving the hands and feet. The usual presentation is an asymptomatic firm plaque that may be red, brown, violaceous, or flesh colored. Lesion size ranges from 1 to $5 \mathrm{~cm}$ [4]. Histological evaluations show a dense array of spindle-shaped tumor cells, slender nuclei, intracellular collagen deposition, and small capillary blood vessels throughout. Metastasis is quite unusual [4], the majority of soft tissue sarcomas metastasize to the lungs. Less frequently reported sites include the retroperitoneum, mediastinum, bones, and rarely the kidney, brain, omentum, scalp, ovaries, liver, and heart [5]. The first case of DFSP metastasis to the thyroid gland was described by Onoda in 1990 [6].

Solitary thyroid nodules are common in clinical practice but nodular intrathyroid metastasis is rare and may be underestimated [7].

The prevalence of intrathyroid metastases of nonthyroid origin ranges from $1.9 \%$ to $25 \%$ [8].

Direct extension into the thyroid may occur in carcinomas of the pharynx, larynx, trachea, and esophagus. Retrograde lymphatic spread into the thyroid has been reported 


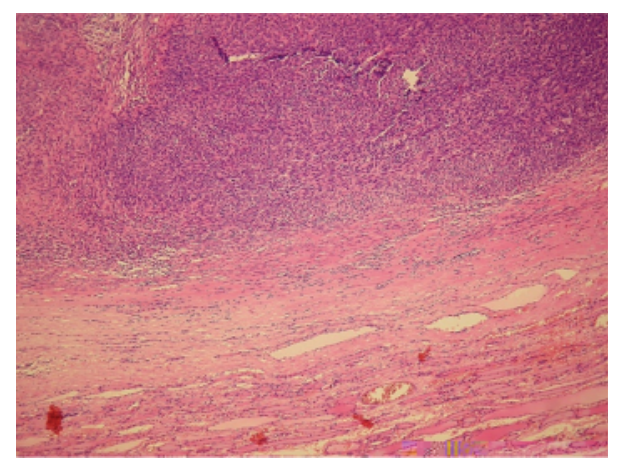

Figure 1: Hematoxylin-eosin staining, 100x, storiform, cellular organized tumor on periphery normal thyroid.

with breast carcinoma as well as hematogeneous metastases to the thyroid, particularly of malignant melanoma, lung, gastrointestinal, breast, and renal cell carcinomas. Rare sources of primary tumors are choriocarcinoma, malignant phylloides tumors, and sarcoma [1].

\section{Case Report}

A 52-year-old woman with a personal history including several surgeries: an appendectomy long ago, extirpation of dermatofibrosarcoma of the inguinal suprapubic region on the left side in 1998, and surgically treated recurrences in 2000, 2001, 2008, and 2009. The last lesion was as large as $8 \times 4 \mathrm{~cm}$. Histological findings were fusiforme and mitotic activity. After last surgical treatment was done local external radiotherapy (66 Gy).

In 2011 she consulted our endocrinology department following the discovery of recent swelling on the right side on her neck, concomitant with worsened swallowing, and mild pain. The thyroid nodule appeared 13 years after diagnosis of sarcoma of the abdominal wall.

Initial physical finding was on the neck palpable large, prominent, markedly firm, mildly painful resistance on right side, no fixation. Pemberton sign positive.

2.1. Differential Diagnosis. We considered several possibilities including metastasis from the known sarcoma or other frequently occurring metastases from carcinomas (renal, breast, gastrointestinal, lung, and melanoma) primary thyroid carcinoma, lymphoma, and benign lesions (adenoma, pseudocyst, and hemangioma).

\subsection{Results of Our Examinations}

Biochemistry. TSH $0.363 \mathrm{mIU} / \mathrm{l}$ ( $\mathrm{N} \quad 0.32-5.0 \mathrm{mIU} / \mathrm{l}$ ), fT4 $14.6 \mathrm{pmol} / \mathrm{l}(\mathrm{N} 9.0-19.0 \mathrm{pmol} / \mathrm{l})$, aTG $1 \mathrm{U} / \mathrm{ml}(\mathrm{N}<1 \mathrm{U} / \mathrm{ml})$, aTPO $1 \mathrm{U} / \mathrm{ml}(\mathrm{N}<1 \mathrm{U} / \mathrm{ml})$, iPTH $6 \mathrm{pmol} / \mathrm{l}(\mathrm{N} 1.48-$ $8.43 \mathrm{pmol} / \mathrm{l})$.

US Thyroid. Right lobe (RL) $50 \mathrm{ml}$, left lobe (LL) $7.3 \mathrm{ml}$, hypoechogenic nodule in middle LL $4 \times 5 \times 7 \mathrm{~mm}$, all RL is filled with hypo- to anechogenic mass pressing the trachea

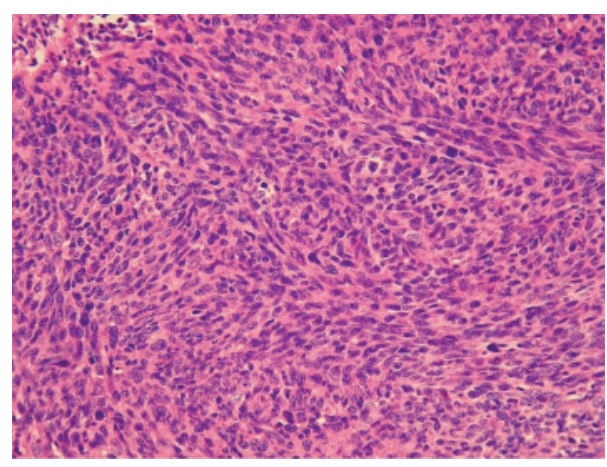

FIGURE 2: Hematoxylin-eosin staining, 400x, markedly tumorous, numerous polymorphs, tumorous cells.

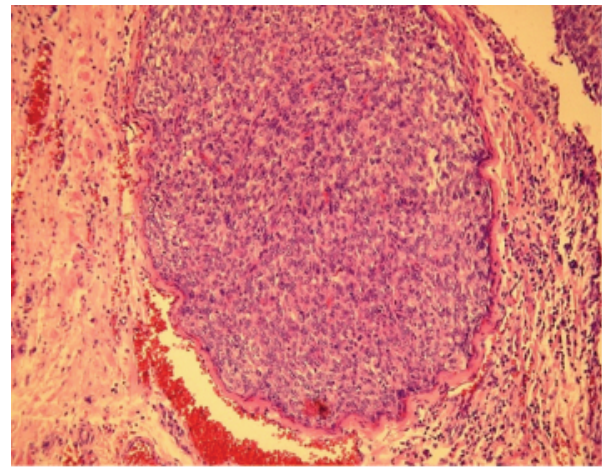

FIgURE 3: Hematoxylin-eosin staining, 200x, tumor angioinvasis.

to the left by $1 \mathrm{~cm}$ and compressing it to $20 \mathrm{~mm}$ (above goiter $34 \mathrm{~mm})$. No pathological lymphatic nodes.

FNAB : Micro. Hemorrhagic background, disperse, isolated clusters of round, and oval pleomorphic nuclei of suspicious appearance were found. Conclusion: Needle Aspiration (FNA) Guidelines Committee IV [29] was category IV/3, that is, suspicious for other primary or secondary malignancies.

CT Neck and Thorax. Voluminous goiter right side, two metastases in lung.

MRI Neck. Nodular goiter right lobe on average $6 \times 4 \times 6 \mathrm{~cm}$, without breakup, spreading retrotrachealy and compressing and deviating the trachea, and enlarged lymphatic nodes on neck were not found.

Laryngoscopy. Vocal cords freely movable.

2.3. Course and Diagnostic Result. The patient was scheduled for surgery following our examinations for mechanical syndrome and FNAB suspicious malignant findings of dermatosarcoma metastasis. She underwent hemithyroidectomy (right lobe and isthmus with tissue volume of about $60 \mathrm{ml}$ ) without complication.

2.4. Histology. Apparent angioinvasion and infiltration surrounding fat and muscle tunic tissue. Immunoprofile of 
TABle 1: Metastatic diseases of the thyroid gland.

\begin{tabular}{|c|c|}
\hline Primary tumor & References \\
\hline Oral cavity carcinoma & {$[9]$} \\
\hline Lingual squamous cell carcinoma & {$[10]$} \\
\hline Parotid gland carcinoma & {$[9,10]$} \\
\hline Nasopharynx carcinoma & {$[9,11]$} \\
\hline Oropharynx carcinoma & {$[9]$} \\
\hline Laryngeal carcinoma & {$[9]$} \\
\hline Esophageal carcinoma & {$[9,10,12-14]$} \\
\hline Cervical paragangliom & {$[15]$} \\
\hline Gastric carcinoma & {$[11,16]$} \\
\hline Pancreatic carcinoma & {$[17]$} \\
\hline Cholangiocarcinoma & {$[11,18]$} \\
\hline Hepatocellular carcinoma & {$[19]$} \\
\hline Colon carcinoma & {$[13,15]$} \\
\hline Merckel cell carcinoma & {$[13,15]$} \\
\hline Breast carcinoma & {$[11,14,15,20]$} \\
\hline Kidney carcinoma & {$[12-14]$} \\
\hline Bladder carcinoma & {$[13,15]$} \\
\hline Prostate carcinoma & {$[14]$} \\
\hline Lung carcinoma & $\begin{array}{c}{[11,13-} \\
15,20,21]\end{array}$ \\
\hline Uterine carcinoma & {$[12-15]$} \\
\hline Neuroendocrine tumors & {$[14,21]$} \\
\hline Malignant phylloides & {$[11]$} \\
\hline Melanoma & {$[15]$} \\
\hline Lymphoma & {$[14]$} \\
\hline Sarcoma & [22-28] \\
\hline
\end{tabular}

tumorous cells, (vimentin strong positive, CD34 focal positive, and CD117 negative). Other helpful methods to differentiate mesenchymal versus epithelial lesions are staining of thyroid transcription factor-1 (TTF-1) and thyroglobulin.

Morphology (epitheloid, more spindle shaped) and marked mitotic activity is indicative for fibrosarcomatous variant dermatofibrosarcoma protuberans (Figures 1, 2, and 3 ). There was an agreement from local abdominal and thyroid histological finding as a metastasis from primary tumor to the thyroid.

Oncologist supplemented examination c-kit (D 117) and considered treatment with imatinib (doxorubicin + ifosfamide) and radiotherapy. Secondarily after hemithyroidectomy were successfully removed bilateral lung-together four-metastases. Condition of the patient is very good.

\section{Discussion}

The thyroid gland is known but unusual site for metastases from sarcomas. There are 10 known cases of leiomyosarcoma metastases to the thyroid, 5 are from primary uterine leyomyosarcoma [22], while there is one case each of metastasis from histiosarcoma of the ankle [23], histiosarcoma of the thigh [24], carciosarcoma [25], liposarcoma of the thigh [26], leiomyosarcoma of the duodenum [27], and leiomyosarcoma of the leg [28]. Other possible and described metastases to the thyroid gland are shown in Table 1 .

Clinically, patients tend to be in the their sixth decade of life or older, usually have a mass on the neck, along with dysphagia, hoarseness, and cold intolerance [23].

Diagnosis of a thyroid nodule as a metastatic lesion is not possible based on clinical and radiological grounds. FNAB is an easy, simple, and useful procedure.

Debulking or thyroidectomy is often indicated to confirm diagnosis and to alleviate any symptoms of neck compression [24].

After surgical management, the administration of systemic therapy is recommended [8].

The prognosis of these patients is grave, although surgical treatment prolongs the time of life (average 34 months with surgery versus 24 without) [12].

This case of dermatofibrosarcoma of the abdominal wall spreading to the thyroid gland is quite rare.

\section{Conclusion}

Metastasis should be considered in any patient with a previous history of malignancy and a new thyroid mass. Diagnosis is possible with FNAB and definitive after surgical treatment with histology. Chemo- and/or radiotherapy may be administered following surgery with various results. In some cases dermatofibrosarcoma protuberans may also be adequately treated with imatinib.

\section{References}

[1] C. D. Scopa, "Histopathology of thyroid tumors. An overview," Hormones, vol. 3, no. 2, pp. 100-110, 2004.

[2] C. Hedinger, E. D. Williams, and L. H. Sobin, "The WHO histological classification of thyroid tumors: a commentary on the second edition," Cancer, vol. 63, no. 5, pp. 908-911, 1989.

[3] J. Rosai, M. L. Carcangiu, and R. A. DeLellis, Tumors on the Thyroid Gland. Atlas of Tumor Pathology, Armed Forces Institute of Pathology, Washington, DC, USA, 1992.

[4] S. V. Labropoulos and E. D. Razis, "Imatinib in the treatment of dermatofibrosarcoma protuberans," Biologics, vol. 1, no. 4, pp. 347-353, 2007.

[5] A. R. Azar, B. Weynand, C. Daumerie, and E. Coche, "Metastatic liposarcoma of the thyroid gland," British Journal of Radiology, vol. 76, no. 910, pp. 750-752, 2003.

[6] N. Onoda, Y. Tsutsumi, K. Kakudo et al., "Pigmented dermatofibrosarcoma protuberans (Bednar tumor). An autopsy case with systemic metastasis," Acta Pathologica Japonica, vol. 40, no. 12, pp. 935-940, 1990.

[7] U. K. Sharma, R. K. Rauniyar, S. Adhikary, and A. Sinha, "Intrathyroid metastasis presenting as a solitary thyroid nodule: an unusual case of clinically silent lung cancer," Kathmandu University Medical Journal, vol. 6, no. 21, pp. 109111, 2008.

[8] G. Dionigi, S. Uccella, M. Gandolfo et al., "Solitary intrathyroidal metatstasis os renal vlear cell carcinoma in a toxic substernal multinodular goiter," Thyroid Research, vol. 1, no. 6, pp. 1-5, 2008.

[9] P. Jankowska, E. M. Teoh, C. Fisher, P. R. Evans, C. M. Nutting, and K. J. Harrington, "Isolated intrathyroid metastasis from 
undifferentiated and squamous carcinoma of the head and neck: the case for surgery and re-irradiation," British Journal of Radiology, vol. 81, no. 966, pp. e154-e161, 2008.

[10] H. Chen, T. L. Nicol, and R. Udelsman, "Clinically significant, isolated metastatic disease to the thyroid gland," World Journal of Surgery, vol. 23, no. 2, pp. 177-181, 1999.

[11] K. Y. Lam and C. Y. Lo, "Metastatic tumors of the thyroid gland: a study of 79 cases in Chinese patients," Archives of Pathology and Laboratory Medicine, vol. 122, no. 1, pp. 37-41, 1998.

[12] M. K. Nakhjavani, H. Gharib, J. R. Goellner, and J. A. Van Heerden, "Metastasis to the thyroid gland: a report of 43 cases," Cancer, vol. 79, no. 3, pp. 574-578, 1997.

[13] E. Mirallié, J. Rigaud, M. Mathonnet et al., "Management and prognosis of metastases to the thyroid gland," Journal of the American College of Surgeons, vol. 200, no. 2, pp. 203-207, 2005.

[14] H. Selimoglu, C. Duran, O. Saraydaroglu et al., "Prostate cancer metastasis to thyroid gland," Tumori, vol. 93, no. 3, pp. 292-295, 2007.

[15] K. Wood, L. Vini, and C. Harmer, "Metastases to the thyroid gland: the Royal Marsden experience," European Journal of Surgical Oncology, vol. 30, no. 6, pp. 583-588, 2004.

[16] H. C. Lee, F. F. Chen, C. C. Lo, C. J. Wang, W. C. Lo, and S. P. Luh, "Metastasis of gastric carcinoma to the thyroid and lung: a case report and review of literature," Journal of Zhejiang University, vol. 11, no. 7, pp. 542-546, 2010.

[17] M. E. Kelly, J. Kinsella, C. d'Adhemar, N. Swan, and P. F. Ridgway, "A rare case of thyroid metastasis from pancreatic adenocarcinoma," Journal of the Pancreas, vol. 12, no. 1, pp. 37-39, 2011.

[18] W. K. Bae, H. J. Shim, Y. D. Choi et al., "Severe hypothyroidism induced by thyroid metastasis of cholangiocarcinoma," Cancer Research and Treatment, vol. 41, no. 1, pp. 56-58, 2009.

[19] H. H. Liang, C. H. Wu, K. W. Tam, C. Y. Chai, S. E. Lin, and S. C. Chen, "Thyroid metastasis in a patient with hepatocellular carcinoma: case report and review of literature," World Journal of Surgical Oncology, vol. 5, article 144, 2007.

[20] T. Y. Kim, W. B. Kim, G. Gong, S. J. Hong, and Y. K. Shong, "Metastasis to the thyroid diagnosed by fine-needle aspiration biopsy," Clinical Endocrinology, vol. 62, no. 2, pp. 236-241, 2005.

[21] H. Yamada, Y. Hasegawa, T. Mitsudomi, T. Nakashima, and Y. Yatabe, "Neuroendocrine tumor metastasis to the thyroid gland," International Journal of Clinical Oncology, vol. 12, no. 1, pp. 63-67, 2007.

[22] D. Nemenqani, N. Yaqoob, and H. Khoja, "Leiomyosarcoma metastatic to the thyroid diagnosed by fine needle aspiration cytology," Journal of the Pakistan Medical Association, vol. 60, no. 4, pp. 307-309, 2010.

[23] M. Vankalakunti, J. Kaur, and R. Srinivasan, "Cytology of sarcoma metastasizing to the thyroid: a case report," Acta Cytologica, vol. 52, no. 6, pp. 729-732, 2008.

[24] P. Gattuso, M. J. Castelli, and C. V. Reyes, "Fine needle aspiration cytology of metastatic sarcoma involving the thyroid," Southern Medical Journal, vol. 82, no. 9, pp. 1158-1160, 1989.

[25] Ö. Mete, N. Özbey, Y. Erbil et al., "Thyroid metastasis of endometrial carcinosarcoma associated with Graves' disease," Gynecological Endocrinology, vol. 23, no. 10, pp. 562-566, 2007.

[26] J. R. Tysome, A. Sandison, and P. M. Clarke, "Myxoid liposarcoma metastatic to the thyroid gland: a case report and literature review," Journal of Laryngology and Otology, vol. 120, no. 6, pp. 511-513, 2006.
[27] B. Bode-Lesniewska, S. Schroder, E. Gemsenjager, M. Staubli, and M. Pfaltz, "Leiomyosarcoma in the thyroid glandprimary or metastatic tumour?" Pathologe, vol. 15, no. 5, pp. 303-307, 1994.

[28] X. R. Deng, G. Wang, C. J. Kuang, G. Z. Peng, and R. S. Chen, "Metastasis of leiomyosarcoma to the thyroid," Chinese Medical Journal, vol. 118, no. 2, pp. 174-176, 2005.

[29] L. J. Layfield, E. S. Cibas, H. Gharib, and S. J. Mandel, “Thyroid aspiration cytology current status," CA-A Cancer Journal for Clinicians, vol. 59, no. 2, pp. 99-110, 2009. 


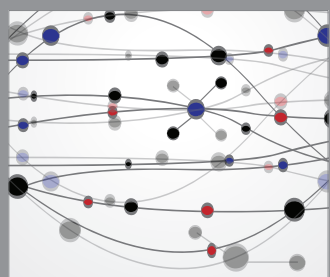

The Scientific World Journal
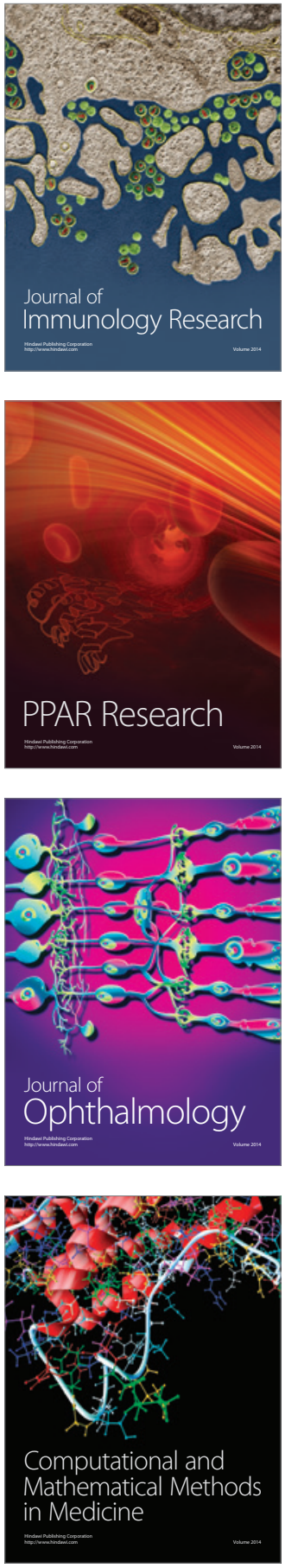

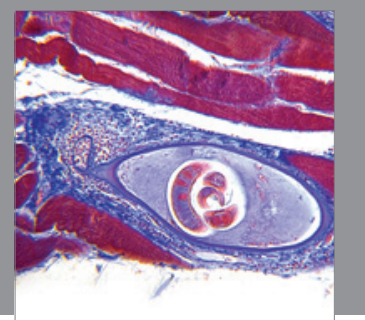

Gastroenterology

Research and Practice
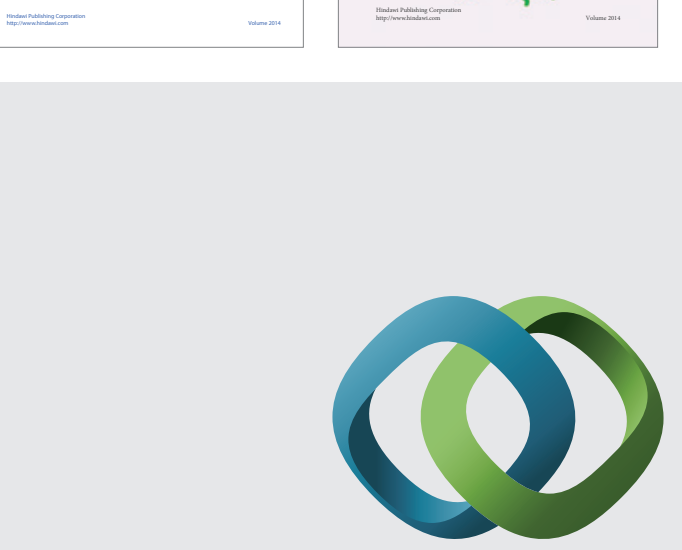

\section{Hindawi}

Submit your manuscripts at

http://www.hindawi.com
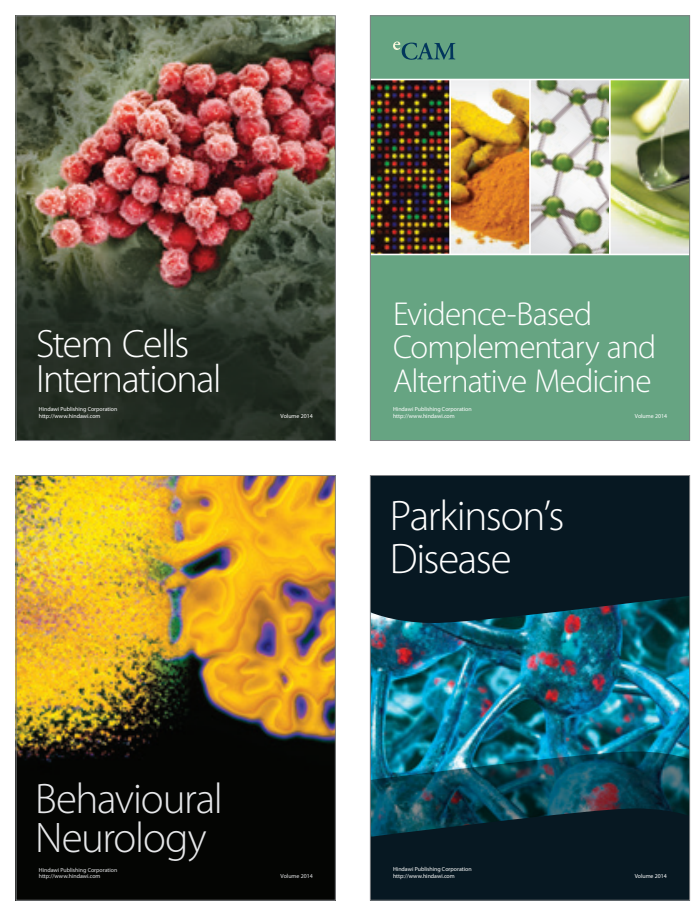

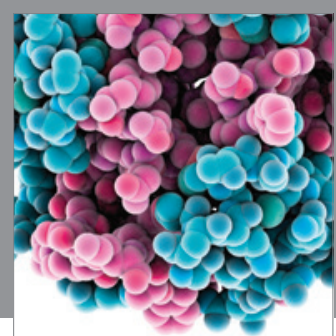

Journal of
Diabetes Research

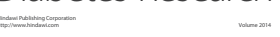

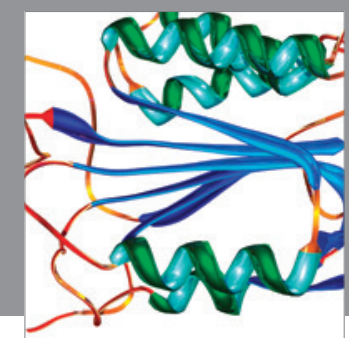

Disease Markers
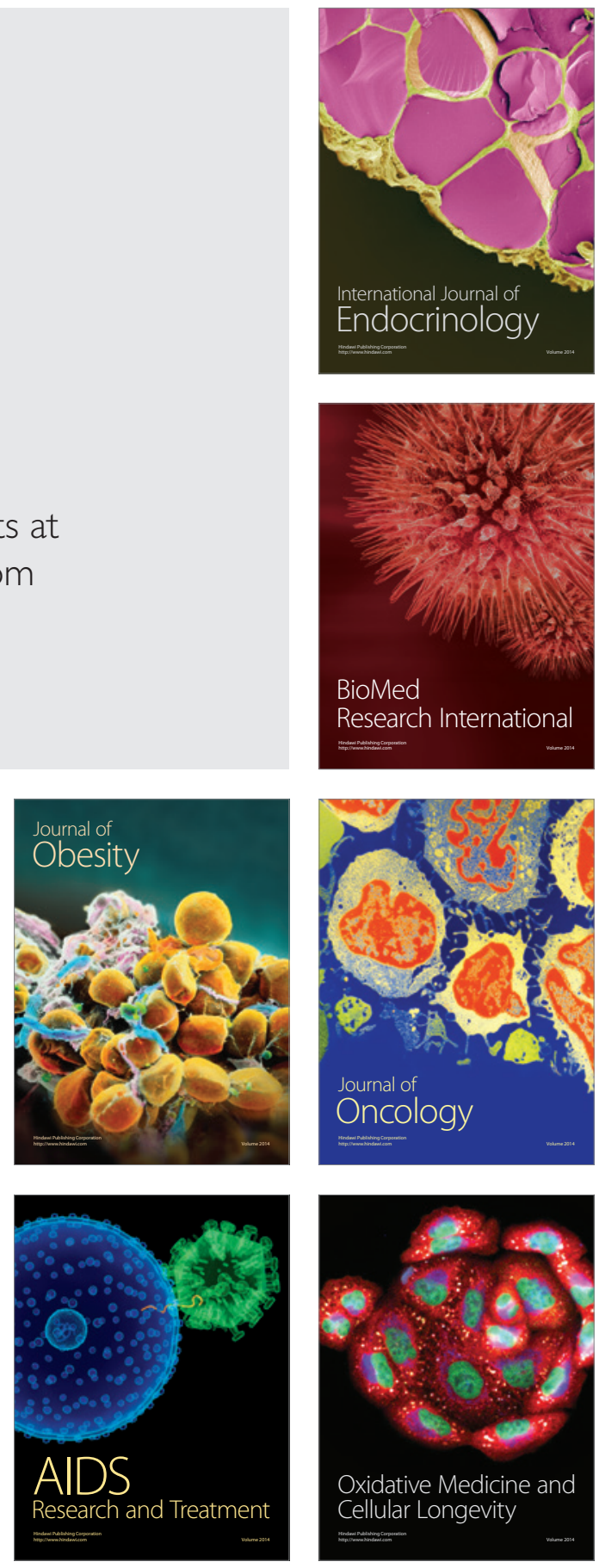